\title{
Apoptosis of bronchoalveolar lavage lymphocytes in hypersensitivity pneumonitis
}

\author{
C. Laflamme, E. Israël-Assayag, Y. Cormier
}

\begin{abstract}
Apoptosis of bronchoalveolar lavage lymphocytes in hypersensitivity pneumonitis. C. Laflamme, E. Israël-Assayag, Y. Cormier. (C)ERS Journals Ltd 2003.

ABSTRACT: The aim of this study was to look at the apoptosis of alveolar lymphocytes in hypersensitivity pneumonitis (HP). HP patients and normal unexposed controls were studied.

The percentage of apoptotic lymphocytes was significantly lower in HP patients than in normal patients $(37.4 \pm 3.4$ versus $56.5 \pm 5.5 \%$ for Annexin $V$ and propidium iodine detection methods and $0.4 \pm 0.1$ versus $1.0 \pm 0.2 \%$ for dUTP nick end-labelling technique (TUNEL)). The proportion of bronchoalveolar lavage (BAL) lymphocytes positive for Fas antigen was significantly higher in $\mathrm{HP}$ patients than in normal subjects $\mathbf{( 7 1 . 7 \pm 5 . 4}$ versus $50.4 \pm 9.0 \%$ ). However, no significant difference was found in the proportion of BAL lymphocytes positive for Fas ligand (FasL) between the two groups. Soluble Fas (sFas) levels in the BAL fluid of the patients and normals were $80.5 \pm 8.5 \mathrm{pg} \cdot \mathrm{mL}^{-1}$ and $23.2 \pm 3.1 \mathrm{pg} \cdot \mathrm{mL}^{-1}$, respectively. A positive correlation was found between the percentage of BAL lymphocytes and the levels of $s F a s$ for the total subjects but not within the separate study groups. The intracellular quantity of the inducible anti-apoptotic gene Bcl-xL product was significantly higher in the pulmonary lymphocytes of HP patients than in lymphocytes of the control, while no difference was found for constitutive antiapoptotic protein (Bcl-2).

In conclusion, the apoptosis of pulmonary lymphocytes is lower in hypersensitivity pneumonitis than in normal subjects. This could be explained, at least in part, by an increase of soluble Fas, the anti-apoptic gene, and Bcl-xL.
\end{abstract}

Eur Respir J 2003; 21: 225-231.

Unité de recherche, Centre de Pneumologie, Hôpital Laval. Institut de cardiologie et de pneumologie de l'Université Laval, Canada.

Correspondence: Y. Cormier

Hôpital Laval

2725 Chemin Ste-Foy

Ste-Foy

Québec

Canada G1V 4G5

Fax: 14186564762

E-mail: yvon.cormier@med.ulaval.ca

Keywords: Apoptosis

inflammation

lung

lymphocytes

Received: October 22001

Accepted after revision: October 22002
Hypersensitivity pneumonitis (HP), an antigeninduced inflammatory lung disease, represents a situation where the immune regulation is disrupted, which leads to the accumulation of large numbers of lymphocytes in the lung [1]. There are three possible mechanisms (not mutually exclusive) by which lymphocytes accumulate in the lung in HP: 1) increased recruitment [2]; 2) local proliferation [3, 4]; and 3) increased survival (decreased apoptosis). This study addresses the issue of decreased lung lymphocyte apoptosis in HP.

During an immune response against foreign antigens, clonal expansion of immunocompetent cells is necessary to mount effective protection. These cells must eventually die off in order to maintain tissue homeostasis [5]. Regulation of cell survival is therefore crucial in limiting the accumulation of potentially harmful cells in the lung. Apoptosis is a physiological, genetically controlled, cellular response to external and internal stimuli whose purpose is to eliminate unwanted cells while preventing damage to surrounding cells or tissue [6]. Apoptosis is often associated with the cross-linking between Fas antigen (Fas or CD95) and its physiological ligand (FasL or CD95L) through cell-to-cell interactions [7]. This pathway can be inhibited by the soluble form of Fas (sFas) [8]. These interactions are often implicated in the regulation of inflammatory cell death, particularly the lymphocytes [9]. Apoptosis of CD4+ T-cells is primarily induced by Fas whereas death of CD8+ T-cells is induced by tumor necrosis factor type 1 receptor (TNFR1) and type 2 receptor (TNFR2) [10].

The Bcl-2 gene family regulates the apoptotic process through the balance of pro-apoptotic (Bax, Bcl$\mathrm{xS})$ and anti-apoptotic products (Bcl-2, Bcl-xL) [11]. Several cytokines can also affect apoptosis. For example, interleukin (IL)-2 can inhibit inflammatory cell apoptosis [12]. This cytokine is upregulated in HP [13].

Another mechanism implicated in the survival of lymphocytes is the B7-CD28 costimulation pathway. CD28, a molecule carried by lymphocytes, is a ligand for $\mathrm{B} 7-1$ and $\mathrm{B} 7-2$ receptors on antigen-presenting cells (APC), such as the alveolar macrophage [14]. CD28 stimulation increases the expression of Bcl-xL and the production of IL-2 through lymphocytes [15]. It has been shown recently that the B7-CD28 costimulation pathway is involved in HP [16, 17]. This pathway could therefore contribute to the accumulation of lymphocytes in HP by an upregulation of certain lymphocyte-specific anti-apoptotic factors.

Having hypothesised that the accumulation of lymphocytes in the lungs of HP could result from decreased apoptosis, the present study was performed 
to quantify and characterise the apoptosis of lung lymphocytes recovered by bronchoalveolar lavage (BAL) from normal subjects and HP patients.

\section{Materials and methods}

\section{Subjects}

A cohort of 39 patients with newly diagnosed HP (all nonsmokers) and 40 nonsmoking normal subjects not exposed to HP antigens were studied. The patients included 32 with farmers' lung (Saccharopolyspora rectivergula), three with humidifier fever (Penicillium sp.), two with bird fanciers' lung (avian protein), one with peat moss HP (Penicillium sp.) and one with sawmill dust exposure (Paecilomyces). All patients were in contact with the antigen up to their lavage and none had received corticosteroids prior to the procedure. In addition, no patient had underlying lung or other diseases. Each experimental subject served for at least one test in this study. The diagnosis of HP was based on previously published criteria [1]. The Laval Hospital's (Quebec, Canada) Ethics Committee approved the study and all subjects signed an informed consent form.

\section{Bronchoalveolar lavage}

BAL was obtained by standard fibroscopy. For the $\mathrm{HP}$ patients, a total of $300 \mathrm{~mL}$ of sterile $0.9 \%$ saline solution was instilled in the middle lobe or the lingula in $50 \mathrm{~mL}$ aliquots. Since normal subjects have low BAL lymphocyte numbers, they underwent a double lavage $(240 \mathrm{~mL}$ in the right middle lobe and $240 \mathrm{~mL}$ in the lingula). Each aliquot was sequentially aspirated and the recovered volume measured. BAL cells were washed with Hank's balanced salt solution, resuspended in Rosswell Park Memorial Institute 1640 medium (Canadian Life Technology, Burlington, ON, Canada) supplemented with $10 \%$ foetal bovine serum and $1 \%$ penicillin-streptomycin, and counted with a haemocytometer. BAL cell viability (trypan blue exclusion) ranged from $90-99 \%$ (average of $95.9 \%$ ). Differential counts for the different inflammatory cells (lymphocytes, macrophages, neutrophils and eosinophils) were performed on a cytospin preparation stained with Diff-Quik (Baxter Diagnostics, Mississauga, ON, Canada). The isolation of BAL lymphocytes was performed using the standard method using a nylonwool column [18]. Using this technique an average of $92 \%$ pure lymphocytes was recovered (range $85-95 \%$ ).

\section{Annexin $V$ and propidium iodine}

The BAL cells were stained using an Apoptosis Detection kit (R\&D System, Minneapolis, MN, USA), according to the manufacturer's instruction. Cytometry analysis of the cells was performed immediately using an EPICS $($ ELITE ESP flow cytometer (Beckmancoulter, Miami, FL, USA). A minimum of 10,000 cells were counted per assay. The appropriate controls were carried out. Annexin-positive and propidium iodine (PI)-negative cells were considered in early apoptosis.

\section{Analysis of in situ deoxyribonucleic acid fragmentation}

Paraformaldehyde-fixed air-dried cytospin preparations were stained by the terminal deoxinucleotidyl transferase (TdT) mediated dUTP nick end-labelling technique (TUNEL) using recombinant TdT (rTdT) [19]. For the assay, the cytospin preparation was fixed for $30 \mathrm{~min}$ in a fresh solution of $4 \%$ paraformaldehyde in a phosphate buffer solution (PBS) $(\mathrm{pH} \mathrm{7.4).} \mathrm{The}$ slides were then washed twice with PBS and incubated in a permeabilisation solution $(0.1 \%$ Triton $\mathrm{X}-100$ in $0.1 \%$ sodium citrate) for $2 \mathrm{~min}$ on ice $\left(4^{\circ} \mathrm{C}\right)$. After another wash with PBS, the area around the sample was dried and a $20 \mu \mathrm{L}$ drop of enzyme solution $(0.3 \mathrm{U}$ rTdT (Canadian Life Technology), $6 \times 10^{-10} \mathrm{M}$ biotin16-dUTP (Roche Diagnostics Canada, Laval, QUE, Canada), $0.1 \mathrm{M}$ potassium cacodylate $(\mathrm{pH} 7.2), 2 \times$ $10^{-3} \mathrm{M} \mathrm{CoCl}_{2}, 2 \times 10^{-4} \mathrm{M}$ dithiothreitol) was added and a cover slip was placed on the sample. The preparation was incubated for $60 \mathrm{~min}$ at $37^{\circ} \mathrm{C}$ in a humidified chamber. After three washes in PBS, $13.5 \mathrm{nM}$ of conjugated fluorescent dye streptavidine-Alexa $488^{\mathrm{TM}}$ (Molecular probes, Eugene, OR, USA) was added in a $20 \mu \mathrm{L}$ drop and kept in the dark for 20 min at $4{ }^{\circ} \mathrm{C}$. Prolong ${ }^{\mathrm{TM}}$ Antifade kit (Molecular probes) was used (according to the manufacturer's protocol) to mount the slides and to avoid fluorescence quenching. For the negative control, rTdT was replaced with enzyme buffer and for the positive control, a pre-incubation with $5 \mathrm{U}$ of Dnase 1 (Amersham Pharmacia Biotech, Piscataway, NJ, USA) was performed immediately before the incubation with the enzyme solution. The count was carried out using an epifluorescence microscope (Nikon Eclipse 6600; Nikon Canada Inc., Quebec, QE, Canada) with the appropriate filter (Nikon filter B2-A, ex: 450-490, em: 505). A minimum of 300 cells were counted on each slide. Two criteria were used to qualify a positive cell (in a late phase of apoptosis): 1) bright green fluorescence on nuclei; and 2) morphological feature of a cell in apoptosis.

\section{Antibodies}

Fluoresecin isothiocynate labelled Bcl-2/100 (mouse immunoglobulin (Ig)G1 antihuman Bcl-2-FITC), D $\times 2$ (mouse IgG1, antihuman CD95-PE (Fas)), NOK-1 (mouse IgG1 antihuman CD95L-PE (FasL)), 2H12 (mouse antihuman Bcl-xL), HIT3a (mouse IgG1 antihuman CD3-PerCP) and the isotype control (mouse IgG1-FITC, mouse IgG1-PE and mouse IgG1-PerCP) were purchased from Pharmingen (San Diego, CA, USA).

Flow cytometry for Fas, FasL and Bcl-2

A total of $2.0 \times 10^{6}$ BAL cells were resuspended in $200 \mu \mathrm{L}$ of PBS $+1 \%$ bovine serum albumin. A batch of 
cells $\left(5 \times 10^{5}\right.$ cell $\left.\cdot 50^{-1} \mu \mathrm{L}\right)$ were labelled with $2 \mu \mathrm{L}$ of anti-CD3 or $2 \mu \mathrm{L}$ of isotype control and placed on ice $(4 \mathrm{C})$ for $45 \mathrm{~min}$. The same protocol was used to label a sample of cells $1.0 \times 10^{6}$ with anti-CD95 $(2 \mu \mathrm{L})$ and anti-CD95L $(2 \mu \mathrm{L})$ and specific isotype controls. The remaining cells $\left(5 \times 10^{5}\right.$ cell in $\left.50 \mu \mathrm{L}\right)$ were permeabilised using a commercial kit (Perm Kit; Pharmingen) before the incubation with anti-Bcl-2 antibodies and its specific isotype control $(2 \mu \mathrm{L}$ of the antibodies, $45 \mathrm{~min}$ on ice).

\section{Evaluation of soluble Fas in bronchoalveolar lavage fluid}

The quantification of sFas in BAL fluids was carried out by a sandwich-type enzyme-linked immunosorbent assay (ELISA) using an OptEIA Human Fas kit (Pharmingen) according to the protocol provided by the manufacturer.

\section{Preparation of the samples for Western blot}

A total of $1 \times 10^{6}$ BAL lymphocytes were purified on nylon-wool columns and resuspended in $20 \mu \mathrm{L}$ of lysis buffer (10 mM Tris-HCl (pH 7.4)), $150 \mathrm{mM} \mathrm{NaCl}$, $2 \mathrm{mM}$ ethylenediamine tetraacetic acid (EDTA), 2\% triton X-100, $1 \%$ of mixture of protease inhibitor (2 mM EDTA, $2 \mathrm{mM}$ polymethylsulfonyl flouride, $1 \mu \mathrm{g} \cdot \mathrm{mL}^{-1}$ of aprotinin, $1 \mu \mathrm{g} \cdot \mathrm{mL}^{-1}$ of leupeptine, all from Sigma) and $20 \mu \mathrm{L}$ of $2 \times$ loading buffer ( $200 \mathrm{mM}$ Tris $\mathrm{HCl}(\mathrm{pH} 6.8), 20 \%$ glycerol, $2 \%$ sodium dodeclysulphate (SDS), $0.0005 \%$ bromophenol blue, $10 \%$ 2-mercapto-ethanol). The mixture was denatured by heating at $100^{\circ} \mathrm{C}$ for $5 \mathrm{~min}$ and then centrifuged at $10,000 \times g$ for $1 \mathrm{~min}$ in order to precipitate phospholipids present in the samples. The supernatant $(40 \mu \mathrm{L})$ was frozen at $-70^{\circ} \mathrm{C}$ until used.

\section{Western blot for Bcl-xL}

The samples $\left(1 \times 10^{6}\right.$ purified BAL lymphocytes $)$ were separated on a $12 \%$ polyacrylamide gel (SDSperflourocarbon-associated gas exchange (PAGE)) and transferred onto a polyvinylidene difluoride membrane. The blot was blocked for $1 \mathrm{~h}$ at room temperature with blocking buffer ( $5 \%$ fat-free dry milk, $0.05 \%$ tween 20 in tris buffered saline) and probed for $1 \mathrm{~h}$ with a monoclonal antibody to Bcl-xL used at a dilution of $1: 100$ in the blocking buffer. The secondary probe (1:100 in blocking buffer), with a goat IgG antimouse IgG horseradish peroxidase (Cedarlane, ON, USA), was detected by chemiluminescence using enhanced chemiluminescence (Amersham Pharmacia Biotech). BAL alveolar macrophages were used as the positive control. The densitometric analysis was performed using Scion Image (Scion Coorperation, MO, USA).

\section{Statistical analysis}

Results are expressed as mean \pm SEM unless otherwise stated. All data were analysed using t-test except for the following: 1) finding as correlation between the percentage of BAL lymphocytes and the concentration of sFAS molecules where a Spearman rank correlation test was used; and 2) working out the proportion of positive lymphocytes where a MannWhitney U-test was applied. A p-value of $<0.05$ was considered significant.

\section{Results}

There was no difference between the proportions of males and females in the two groups of subjects studied. The average age of the HP subjects was higher than that of the normal subjects. The percentage and number of the various BAL inflammatory cells for each group of subjects was similar to that previously published [16] (table 1). The CD4:CD8 ratios in BAL lymphocytes for 28 of the $39 \mathrm{HP}$ cases and for 14 of the 40 normal controls were assayed for each group. The ratio for the HP patients ranged from $0.1-10.6$ mean \pm SD $(2.0 \pm 2.8)$ and the ratio for normal control ranged from $0.3-5.1(1.7 \pm 1.2)$. There was no significant difference between the two groups. This result is in agreement with the finding of ANDo et al. [20] that the CD4:CD8 ratio is not a good parameter for characterising the BAL lymphocyte population in HP.

The BAL lymphocytes of HP subjects were less Annexin+/PI- than those of normal subjects $(37.4 \pm 3.4 \%$ $(n=18)$ versus $56.5 \pm 5.5(n=15)$, respectively, $p=0.004$; fig. 1a). To confirm this result, cytospins of BAL cells were tested by TUNEL in a subgroup of the subjects. Fewer BAL lymphocytes of HP patients were TUNEL positive than those from healthy subjects $(0.4 \pm 0.1 \%(\mathrm{n}=9)$ versus $1.0 \pm 0.2(\mathrm{n}=7), \mathrm{p}=0.033$; fig. $1 \mathrm{~b})$. Positive and negative controls were included for each experiment. Positive controls (cell preincubated with deoxyribonucleic acid (DNA)) gave $100 \%$ of positive cells. Negative controls (TUNEL assay without TdT) gave $0 \%$ of positive cells.

As shown in figure $2 \mathrm{a}$, the percentage of positive lymphocytes for Fas was $~ 50 \%$ higher in HP patients than in normal subjects $(68 \pm 5.4 \%(n=18)$ and $46.7 \pm 9.0$ $(\mathrm{n}=9)$, respectively, $\mathrm{p}=0.004)$. This result is in agreement with the data of Agostini et al. [21]. The proportion of positive lymphocytes for FasL was also determined. As shown in figure $2 b$, no significant

Table 1.-Characteristics and bronchoalveolar lavage of hypersensitivity pneumonitis (HP) patients and normal controls

\begin{tabular}{lcc}
\hline & HP & Normals \\
\hline Subjects n & 39 & 40 \\
Sex & & \\
$\quad$ Male & 25 & 26 \\
Female & 14 & 14 \\
Age yrs & $48.9 \pm 14.2$ & $25.8 \pm 4.1$ \\
Cells mL $\times 10^{3}$ & $734.8 \pm 14.2$ & $102.1 \pm 44.7$ \\
\% lymphocytes & $56.6 \pm 17.5$ & $9.9 \pm 6.8$ \\
$\%$ macrophages & $34.2 \pm 18$ & $87.9 \pm 8$ \\
\% neutrophils & $7.1 \pm 8$ & $1.7 \pm 1.8$ \\
\hline
\end{tabular}

Data are presented as mean \pm SD. 
ๆ
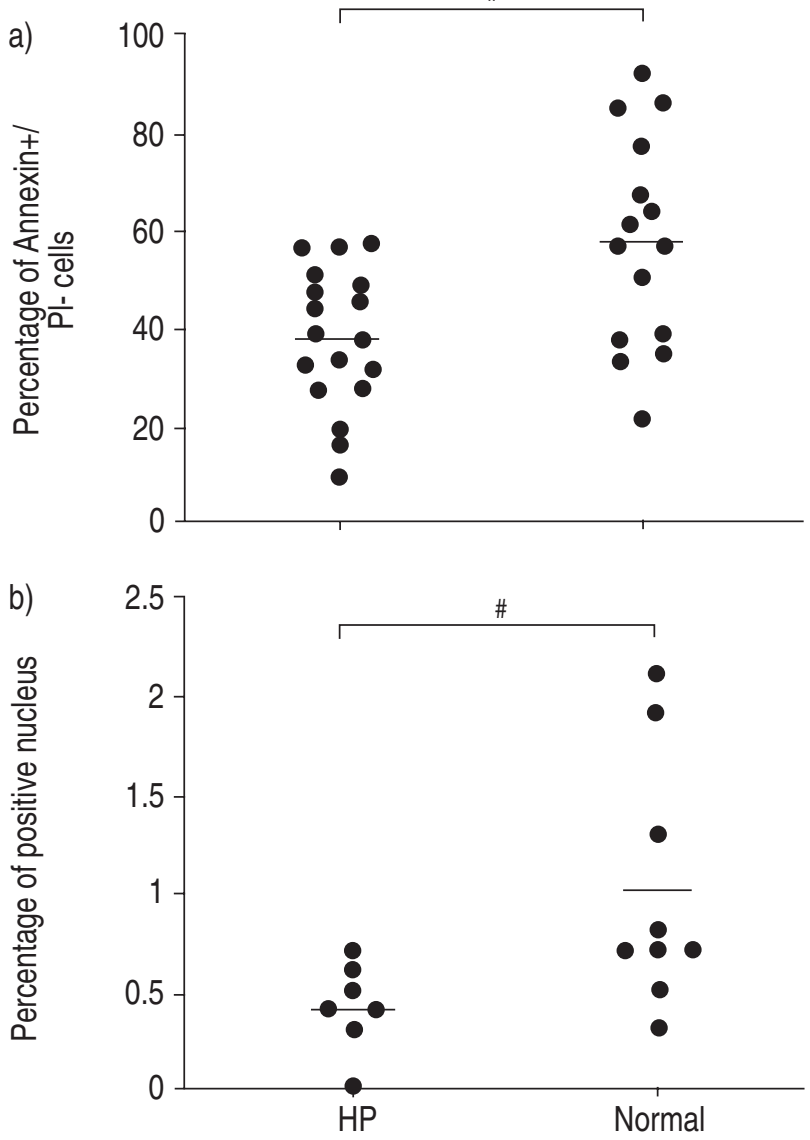

Fig. 1. - Evaluation of bronchoalveolar lavage, lymphocyte apoptosis in hypersensitivity pneumonitis (HP) patients and normal subjects. a) Double probing Annexin V and propidium iodide (PI) technique used to asses the number of cells in early apoptosis. b) A dUTP nick and labelling technique used to assess the final phase of apoptosis. Solid line represents the mean value. \#: $\mathrm{p}=0.033 ;{ }^{\uparrow}: \mathrm{p}=0.004$.

difference was found in the proportion of BAL lymphocytes positive for FasL $(84.9 \pm 5.7(n=12)$ and 95.6 $\pm 3.2(\mathrm{n}=6), \mathrm{p}=0.23)$, respectively, for HP patients and normal subjects.

The quantity of sFas present in the BAL fluid was more than three-fold higher in HP patients compared to normals $\left(80.5 \pm 8.5 \mathrm{pg} \cdot \mathrm{mL}^{-1}(\mathrm{n}=23)\right.$ versus $23.2 \pm 3.1$ $(\mathrm{n}=14), \mathrm{p}=0.0001$; fig. 3$)$. No correlation was found between sFas concentration in BAL fluid and the proportion of Fas-positive lymphocytes (data not shown). For the total subjects (HP plus normal), a positive correlation was observed between the percentage of BAL lymphocytes and the concentration of $\mathrm{sFas}\left(\mathrm{R}^{2}=\right.$ $0.38, p=0.0001$; fig. 4a). An increase of $s F a s$ molecules was expected in the presence of a higher number of BAL lymphocytes since these cells are major producers of this molecule. A negative correlation $\left(\mathrm{R}^{2}=0.24\right.$, $\mathrm{p}=0.0058$; fig. $4 \mathrm{~b}$ ) was found between the percentage of lymphocytes and the percentage of cells in apoptosis (Annexin/PI test). However, the correlation was not significant within the separate study groups. In addition, no correlation (data not shown) was found between the concentration of sFas and the percentage of cells in apoptosis (Annexin/PI test).
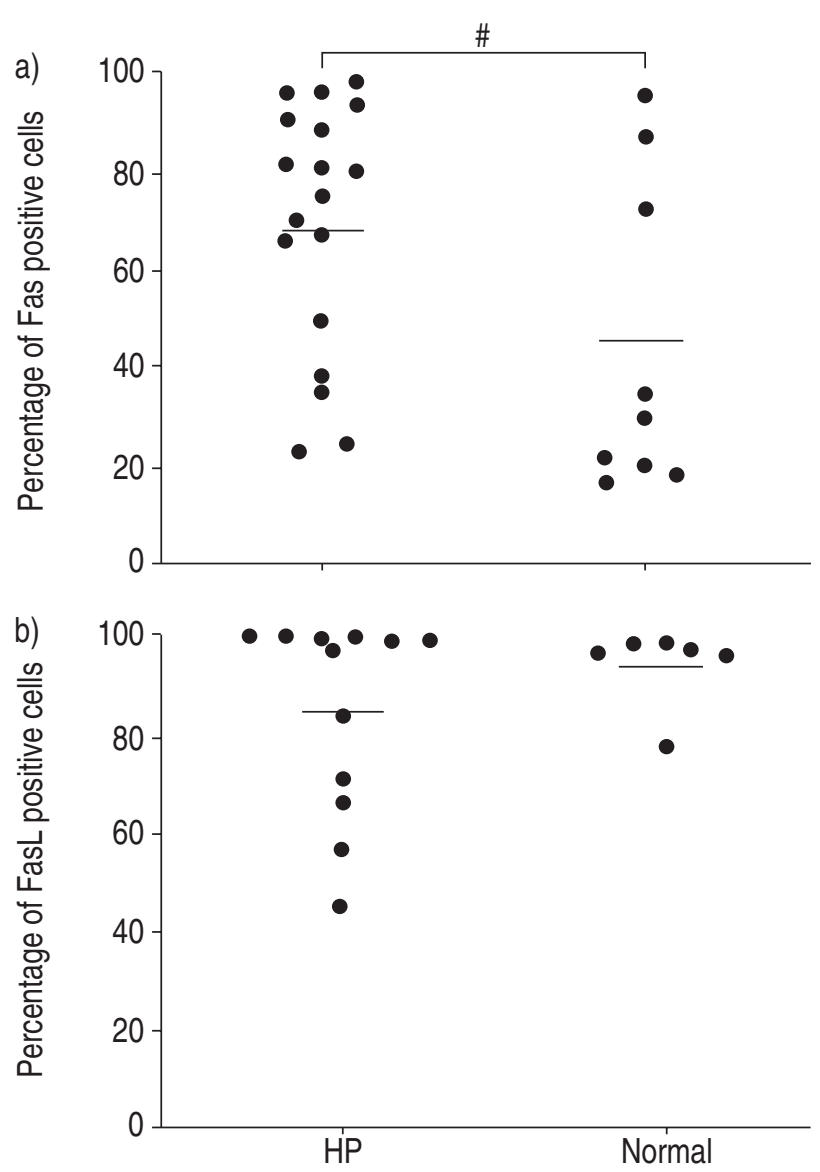

Fig. 2.-Percentage of bronchoalveolar lavage lymphocytes positive for the surface receptors of a) Fas and b) Fas ligand in hypersensitivity pneumonitis (HP) patients and normal subjects. Solid line represents the mean value. ${ }^{\#}: \mathrm{p}=0.004$.

No significant difference was found in the propor-

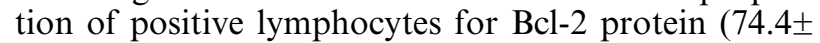
$7.71 \%(\mathrm{n}=6)$ versus $93.1 \pm 2.8 \quad(\mathrm{n}=5), \mathrm{p}=0.066$; fig. 5). However, the intracellular level of $\mathrm{Bcl}-\mathrm{xL}$ (figs. $6 \mathrm{a}$ and b) was increased by more than two and a half

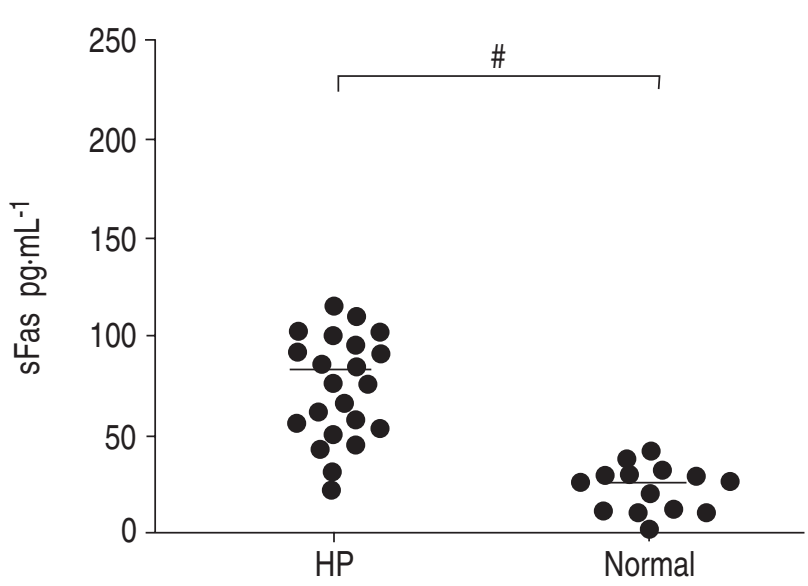

Fig. 3.-Quantification of soluble Fas (sFAS) in bronchoalveolar lavage in hypersensitivity pneumonitis (HP) patients and normal subjects. Solid line represents the mean value. ${ }^{\#}$ : $\mathrm{p}=0.0001$. 

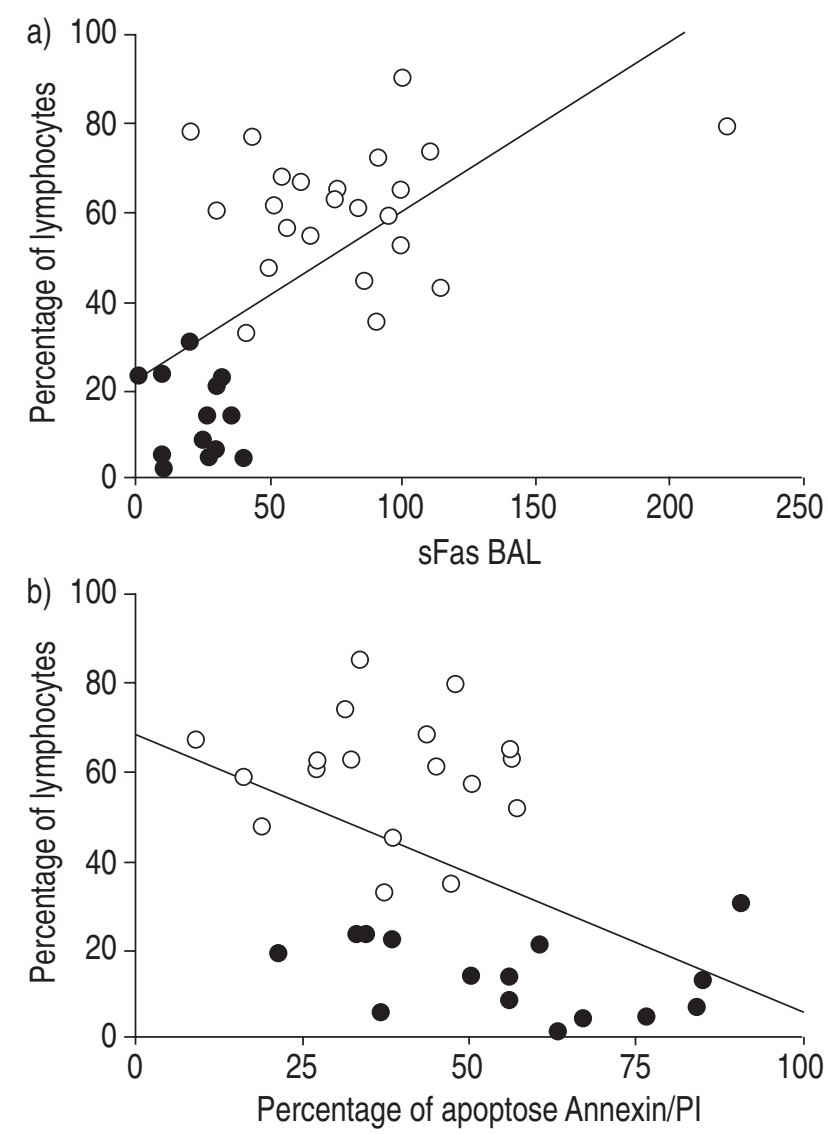

Fig. 4.-Correlation between bronchoalveolar lavage (BAL) lymphocytosis and a) the concentration of soluble Fas (sFas) and b) the percentage of Annexin $\mathrm{V}$ and propidium iodine (PI) cells. $O$ : hypersensitivity pneumonitis (HP) patients; 0 : normal subjects. Solid line represents mean value.

times in the BAL lymphocytes of HP compared to normals $(9.9 \pm 3.3(\mathrm{n}=6)$ versus $3.8 \pm 1.9(\mathrm{n}=7), \mathrm{p}=0.03$; fig. 6b). Figure 6 a shows representative results on Western blotting. The measure was performed with

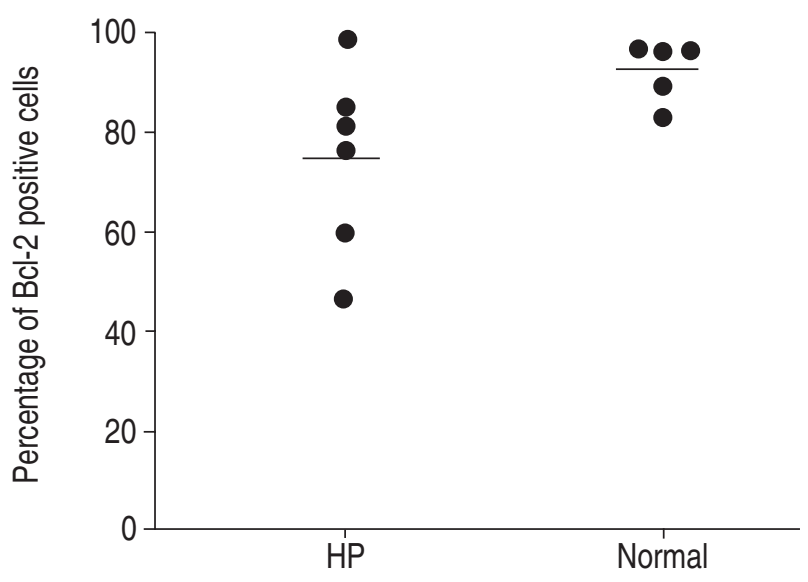

Fig. 5.-Proportion of bronchoalveolar lavage lymphocytes positive for Bcl-2 in hypersensitivity pneumonitis (HP) patients and normal subjects. Solid line represents mean value. a)
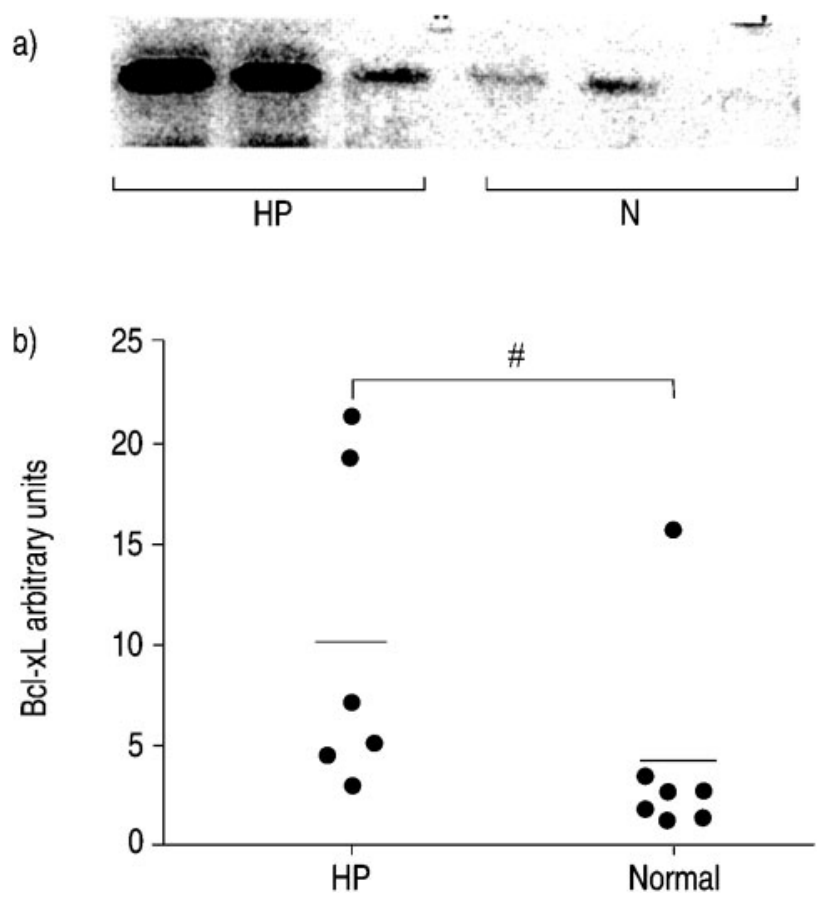

Fig. 6.-Quantification of the Bcl-xL protein in the bronchoalveolar lavage lymphocytes found in hypersensitivity pneumonitis (HP) patients and normal subjects. a) Representative result of the Bcl-xL protein bands demonstrated by Western blot showing higher expression in three HP patients compared to three normal controls. b) The bands were quantified by densiometry software (Scion Image).

the densitometry software Scion Image and the unit was arbitrary.

\section{Discussion}

This study shows, by two different techniques, that the apoptosis of BAL lymphocytes is decreased in HP compared to BAL lymphocytes of normal subjects. Therefore, the lymphocytosis characteristic of HP could be explained, at least partly, by a reduction in the apoptosis of the pulmonary lymphocytes.

The results cannot quantify the relative importance of apoptosis in the maintenance of pulmonary inflammation in HP, but suggest it could be a significant one. Although all of the tests were not performed on the BAL cells of all subjects in each group, the marked differences between the groups is clearly shown by the studies performed.

The presence of fewer apoptotic lymphocytes and an increase in the number that are Fas positive at first seems contradictory. The anticipated higher percentage of apoptosis associated with Fas expression was probably overshadowed by the increased concentration of the soluble Fas and by the increased intracellular Bcl-xL. The ligation of Fas/FasL is a cell-to-cell interaction often implicated in the initiation of apoptosis. sFas binds to FasL, therefore limiting the number of this pro-apoptotic receptor on activated lymphocytes [22]. Shedding of sFas is an inflammatory mechanism by which the immune system can prolong 
the viability of lung lymphocytes and this is what appears to happen in HP. The possibility of a failure in the initiation of the apoptosis by the Fas/FasL cannot be eliminated. For example, an overproduction of the $\mathrm{Bcl}-2$ protein in lymphocytes in culture (of Jurkat type) inhibits the Fas-induced apoptosis [23]. Also, an overproduction of Bcl-xL in MCF7 cells (humoral epithelial cells) expressing Fas makes these cells resistant to Fasinduced apoptosis [24].

Although this study confirms that pulmonary lymphocytes in HP patients express more Bcl-xL than those from normal subject, it is unknown whether the intracellular level of Bcl-2 is increased. A positive cell can contain an unknown quantity of Bcl-2 (limit of detection of the test to a maximum concentration). Western blot techniques will be needed to further evaluate the implication of the $\mathrm{Bcl}-2$ protein in the reduction of apoptosis in HP.

The increase in the intracellular levels of Bcl-xL of the BAL lymphocytes in HP could be related to the increase in costimulation via the B7-CD28 pathway. Indeed, as previously mentioned, this pathway is unregulated in HP. An increase in costimulation B7-CD28 is known to increase resistance to lymphocyte apoptosis mediated via the intracellular increase of the Bcl-xL protein and by increased expression of IL-2, a survival factor for these cells [15].

An interesting question raised by the results of this study is whether the reduction in the apoptosis of the BAL lymphocytes in HP is due to an intrinsic modulation of the cells themselves and/or to the pulmonary micro-environment they were collected from. It is possible that other anti-apoptotic factors, other than $\mathrm{Bcl}-\mathrm{xL}$ and sFas, present in the pulmonary environment, could participate in the decrease of lymphocyte apoptosis.

Further studies are needed to elucidate the mechanisms involved in the control of lymphocyte survival in HP. The effect of the micro-environment would require in vitro studies looking at the effect of antiapoptotic cytokines on BAL lymphocytes. For example, purified BAL lymphocytes of HP patients and control subjects could be cultured with Fas agonist and IL-2 in order to evaluate these different stimulations on the lymphocyte apoptosis in time. Further work is also needed to investigate the relevance of these findings to the development of HP because it has been shown that lymphocytosis also occurs in the lungs of exposed individuals who remain asymptomatic [25].

\section{Conclusions}

This study shows that a decrease in lymphocyte apoptosis may be involved in the alveolar lymphocytosis seen in hypersensitivity pneumonitis. Potential mechanisms for the increased survival of these lymphocytes include high levels of soluble Fas, enhanced $\mathrm{Bcl}-\mathrm{xL}$, and the presence of anti-apoptotic cytokines in the lungs.

\section{References}

1. Cormier Y, Schuyler M. Part M: Interstitial lung disease. In: Bone RC, ed. Hypersensitivity Pneumonitis Textbook of Pulmonary Medecine, Vol 2. St Louis, Mosby-year book, 1992; pp. 1-9.

2. Oshima M, Maeda A, Ishioka S, Hiyama $\mathrm{K}$, Yamakido M. Expression of C-C chemokines in bronchoalveolar lavage cells from patients with granulomatous lung diseases. Lung 1999; 177: 229240.

3. Israël-Assayag E, Cormier Y. Surfactant modifies the lymphoproliferative activity of macrophages in hypersensitivity pneumonitis. Am J Physiol 1997; 273: 1258 1264.

4. Trentin L, Migone N, Zambello R, et al. Mechanisms accounting for lymphocytic alveolitis in hypersensitivity pneumonitis. J Immunol 1990; 145: 2147-2154.

5. Hetts SW. To die or not to die. An overview of Apoptosis and its role in disease. JAMA 1998; 279: 300-306.

6. Thompson CB. Apoptosis in the pathogenesis and treatment of disease. Science 1995; 267: 1456-1462.

7. Nagata S, Golstein P. The Fas death factor. Science 1995; 267: 1449-1456.

8. Cheng J, Zhou T, Liu C, et al. Protection from Fasmediated apoptosis by a soluble form of the Fas molecule. Science 1994; 515: 1759-1762.

9. Ju ST, Panka DJ, Cui H, et al. Fas(CD95)/FasL interactions required for programmed cell death after T-cell activation. Nature 1995; 6513: 444 448.

10. Ware CF, VanArsdale S, VanArsdale TL. Apoptosis mediated by the TNF-related cytokine and receptor families. J Cell Biochem 1996; 60: 47-55.

11. Adams J, Cory S. The Bcl-2 protein family: arbiters of cell survival. Sciences 1998; 281: 1322-1326.

12. Boise LH, Minn AJ, Thompson CB. Receptors that regulate T-cell susceptibility to apoptotic cell death. Ann N Y Acad Sci 1995; 766: 70-80.

13. Dakhama A, Israël-Assayag E, Cormier Y. Role of interleukin-2 in the development and persistence of lymphocytic alveolitis in farmer's lung. Eur Respir $J$ 1998; 11: 1281-1286.

14. Harris NI, Ronchese F. The role of B7 costimulation in T-cell immunity. Immunol Cell Biol 1999; 77: 304 311.

15. Boise LH, Minn AJ, Noel PJ, et al. CD28 costimulation can promote T-cell survival by enhancing the expression of Bcl-xL. Immunity 1995; 3: 87-98.

16. Israël-Assayag E, Dakhama A, Lavigne S, Laviolette M, Cormier Y. Expression of costimulatory molecules on alveolar macrophages in hypersensitivity pneumonitis. Am J Respir Crit Care Med 1999; 159: 1830-1834.

17. Israël-Assayag E, Fournier M, Cormier Y. Blockage of T-cell costimulation by CTLA4-Ig inhibit lung inflammation in murine hypersensitivity pneumonitis. J Immunol 1999; 163: 6794-6799.

18. Eisen SA, Wedner HJ, Parker CW. Isolation of pure human peripheral blood T-lymphocytes using nylon wool columns. Immunol Commun 1972; 1: 571-577.

19. Gavrieli Y, Sherman Y, Ben-Sasson SA. Identification of programmed cell death in situ via specific labeling of nuclear DNA fragmentation. J Cell Biol 1992; 119: 493-501.

20. Ando M, Konishi $\mathrm{K}$, Yoneda R, Tamura $\mathrm{M}$. Difference in the phenotypes of bronchoalveolar lavage lymphocytes in patients with summer-type
Acknowledgements. The authors would like to G. Tremblay and M. Laviolette for their helpful discussions. 
hypersensitivity pneumonitis, farmer's lung, ventilation pneumonitis, and bird fancier's lung: report of a nation wide epidemiologic study in Japan. J Allergy Clin Immunol 1991; 87: 1002-1009.

21. Agostini C, Zambello R, Sancetta R, et al. Expression of tumor necrosis factor-receptor Superfamily members by lung $\mathrm{T}$ lymphocytes in interstitial lung disease. Am J Respir Crit Care Med 1996; 153: 1359-1367.

22. Tanaka M, Itai T, Adachi M, Nagata S. Downregulation of Fas ligand by shedding. Nat Med 1998; 1: $31-36$.
23. Kawahara A, Kobayashi T, Nagata S. Inhibition of Fas-induced apoptosis by Bcl-2. Oncogene 1998; 17: 2549-2554.

24. Medema JP, Scaffidi C, Krammer PH, Peter ME. Bcl$\mathrm{xL}$ acts downstream of caspase- 8 activation by the CD95 death-inducing signaling complex. $\mathrm{J}$ Biol Chem 1998; 273: 3388-3393.

25. Gariepy L, Cormier Y, Laviolette M, Tardif A. Predictive value of bronchoalveolar lavage cells and serum precipitins in asymptomatic dairy farmers. $\mathrm{Am}$ Rev Respir Dis 1989; 140: 1386-1389. 